\title{
Sports Organization and Governance in India
}

\author{
Diksha Garewal Das
}

Assistant Professor at School of Law, Jagran Lakecity University, Bhopal, MP, India

\section{Introduction}

Sports activities have always been remained dynamical and have made relations between nations who were once fighting against each other at war(s). Earlier, hunting and fighting were commonly used as recreational activities or for leisure. ${ }^{1}$ Sports activities get countries together for a common goal and purpose. Sports demonstrate how the society has been transformed from Vedic times to present. Chess, polo, wrestling, bow \& arrow are some of the games that began in India during the Vedic times. Sports evolved through times, and now it is an integral part of our society.

As we know that sports activities now do not only confine to leisure but more than that, it is a profession now for sportsperson and other people involved in it. Society's development led to the development of sports also, which made it more complex and organized in nature. Sports were considered and played as a reputation of a nation and during a sports event nation's pride was at stake. Olympics development changed the dynamics of whole sports activities, it led to overall growth and development of sports culture at the global level. ${ }^{2}$ Different sports were represented at international level, as teams represented their country under various different activities in Olympic Games.

Similarly, India has seen development in sports and Indian teams' represents the nation in various sports events been played at an international level like Asian Games, World Tournaments etc. In India, sports is regulated and governed by governing bodies. These bodies organise, conduct and promote sports events. Like hosting and organizing Asian games, Commonwealth games, world cup for cricket, hockey etc. in India. Along with changing dynamics of sports India has also seen the poor administration and regulation in sporting activities recently, due to which the desired and objectives could not be achieved as targeted by the country, like poor performance by sportspersons. Loopholes in administration, with no minimum facilities for athletes, infrastructural problems, financial scams etc.

\section{Sports Organisation and Governance}

Sports have not only been considered as a recreational activity but it is a pride of a nation. It is a way forward to education, development; promote health etc. which has been also mentioned in the United Nations resolution adopted in the year 2003, by the General Assembly. ${ }^{3}$

\footnotetext{
${ }^{1}$ Grant Jarvie, Sport, Culture and Society: An Introduction.

${ }^{2}$ Jitendra Choudhary and Jayat Ghosh, Governance of Sports in India, 2013.

${ }^{3}$ Bhagirath Ashiya, The Sport, Money and Law: Transforming Indian Sports Administration Through Competition law, ICLR Vol. 1 .
}

This increased in the number of overall participation by countries and players. This would demand more support from administration to be more active and provide facilities for the sports activities and participants. With the changing times, there has been professionalization of sports globally, which includes international viewers, customers, and it has also created a big market for commodities to be traded. Professionalization of sports has different advantages like awareness of education, performance standards to be followed, wages (minimum), and investments in sports activities. ${ }^{4}$ With the new and developing sports industry more finance is required which the problem is often of nations. There is also the question regarding the present model of governance with the changing scenario. Should the government's role in governance model be more active and direct?

Now dealing with the present model of governance in India, which includes the governing bodies like:

- Ministry of Youth Affairs and Sports (MYAS)

- National Sports Federation (NSF)

- Indian Olympic Association (IOA)

- State Olympic Association (SOA)

- Sports Authority of India (SAI)

Governing bodies guides the sport's governance in the country. These are government and autonomous bodies with their specific objectives of overall growth and development of sports activities. The responsibility of MYAS and SAI is to assist financially and also provide infrastructure, while, IOA and SOA are autonomous bodies and their function is to provide assistance to represent the nation at global events and tournaments, this also includes sports promotion and organisation of games events at national level. Along with these governing bodies

Some other governing bodies specially established to promote and conduct non- Olympic games, like cricket, that is controlled and regulated by the BCCI, Athletics Federation of India, All India Football Federation, Hockey India etc ${ }^{5}$. these autonomous bodies are affiliated to the international bodies for the same, Generally, there is no government intervention as it is restricted by these international federations as per their charters, which is also protection to these federations. All these bodies and federations are registered under the Societies Registration Act of XXI, 1860 as societies.

\footnotetext{
${ }^{4}$ Adam Lewis QC and Jonathan Taylor, 'Government Intervention in the Sports Sector' in (eds), Sport: Law and Practice (3rd ed., Bloomsbury, London 2003)

${ }^{5}$ Mukul Mudgal, Law and Sports in India: Development, Issues and Challenges, Lexis Nexis Butt erworths

Wadhwa, 2011.
} 
MYAS is under the Political Responsibility, headed by the cabinet minister and same is managed by the National Sports Federations (NSFs). BCCI is neither regulated nor controlled by NSF. At present, there are 70 NSFs in the country.

Sports Authority of India (SAI) is behind all kinds of support to the ministry. It provides infrastructure, all required equipment for training purpose, and coaching, training facilities to the youth who see future in sports activities, which makes them competition ready.

Now, Indian Olympic Association (IOA) which was established by the Dorabji Tata in the year 1927, the association is mainly responsible for Indian teams' participation in Olympics, Asian, South- Asian and Commonwealth Games. National Federations and State Olympic Associations are affiliated and recognized by $\mathrm{IOA}^{6}$.

Selections into national team are done by the respective National Federations and then recommendation goes to the IOA for the official sponsorship for the participation in the games under the International Olympic Committee, Olympic Council of Asia, Commonwealth Games Federation and South Asian Games.

Similarly, the State Olympic Association (SOA) is equipped with the task to promote Olympic Sports which includes ensuring cooperation from other sports association of different states for the purpose.

These governing bodies also receive financial cooperation and aid from the government that also includes tax benefits and indirect subsidies. These bodies are headed by the retired politicians and other expert eminent personalities.

\section{Issues and Challenges}

For any profession to develop and succeed, it should have a good organisational structure, administration and management skills. This is same with sports administration and governance also. It has moved towards commercialization and professionalism, which requires more competitiveness among sportsperson to survive. ${ }^{7}$ Administration and present governance model is not fulfilling the objectives and goals. There has been a downfall in the quality of performance by sportsperson, which is also a result of the inefficiency of administration, corruption in the governance of sports, political control, nepotism, no infrastructure development and functional issues among the administration itself.

As we also know the very fact that success of any sport depends on its organisation, administration, and management, out of which management is the most important and plays a key role in planning, programming and executing.

\footnotetext{
${ }^{6}$ Need for Sports law in India, IAS SCORE(2015).

${ }^{7}$ Poor governance in sports, reasons for failure of athletes, Times of India (Aug 10, 2017).
}

There are some other issues and challenges related to sports administration that mostly includes no define code, legislation or rules governing the sports administration which also includes the funding, elections for various administrative posts, years in office etc. associations work accordingly, with their own rules and constituencies, which are generally not fair and transparent in nature for both the players and for the officials too. For example like the same person holding the same position for last 20 years in a federation.

Sports administrative bodies should have proper and sufficient representations from ex-sportsperson, in which they lack. These bodies have administration staff that is generally not from sports field that ultimately brings more issues, as the untrained staff with no experience in sports cannot supervise or handle problems of sportspersons. ${ }^{8}$

The issue of inadequate funding to sports that is comparatively less than other countries. In India, most of the funding comes from the governmental whereas, in the countries like The USA most of its sports funding comes from the private organizations. Under the CSR, corporate firms or other companies are also interested in investing into sporting activities, but unfortunately, due to lack of transparency in the governance system, these companies do not come forward to invest or promote sports. So the need of the hour is to improve transparency in the governance model for sports activities to bring in more investments, sponsorships, and funding.

The other major problem of sports in India is the lack of sports infrastructure at grass root level, which includes no hierarchy from the very grass root level to the national level. No training or teachings at the block or district level to children who wish to be athletes and their talent is not nurtured properly and in the correct direction, as a result, the country loses talents. To overcome this issue there should be the establishment of sports association at the block, district levels to facilitate them with required training and coaching. Also, a transparent administration to look after their training, proper nutritional plan, awareness programmes for them, to nurture them for future.

To bring transparency in workings of sports association and administration, the possible solution is also to bring the egovernance, where all sports related data can be stored, regarding budget, funding, sponsorships by different organizations and institutions. ${ }^{9}$ The transparency issue could be possibly solved if these bodies bring under the parameter of RTI, (which has been also put forward by the MYAS but being opposed by the BCCI).

We are not new to the fact that many athletes come from villages and poor background with not much education, they entirely depend on their coaches and other support staff members for everything. It is the responsibility of their

\footnotetext{
${ }^{8}$ Role of government in promoting sports in India: A critical Evaluation, Sports Digest (Aug 19, 2011).

${ }^{9}$ Juthika Mehta, sports organisation and administration in Indian Sports, IISM(Mar 24, 2017).
} 
coach and support staff to look and guide them with their nutrition diet so that they do not consume anything unknowingly which falls under the prohibited list of substances ${ }^{10}$. There have been cases where athletes are being found positive in the doping test due to consumption of prohibited substances. This can be probably due to lack of knowledge and guidance on the prohibition on the consumption of certain herbs or substances in their diet.

There are some other issues also behind underdevelopment of sports, like inequalities issues, a number of women participants. Less of infrastructure facilities, which are the major hindrance to the development of sports in the country $^{11}$, availability of such facilities only to few sections of society that creates inequalities, which also affects the quality of sports in the country.

Drawbacks in policies, there is no legislation and regulation governing sports in the country that affects adversely to the sports industry.

\section{Governance Model of Other Countries}

USA: In USA there is no coordinated model of sports governance, all sports governing bodies work as a parallel system. There exists no formal governance system for sports in the country. Institutions outside the role of government are mostly responsible for the growth and development of sports. ${ }^{12}$ Its free economy and lack of government control also reflect in the sports industry. At the Federal level, there are only three policies that talks about sports indirectly.

CHINA: Before adopting the open-door policy by China, the sports industry was highly influenced and run by the state. The Chinese government also funded, sponsored sports affairs, this also included a centralized system and plans for sports activities. New policy led to the change and transformation in sports system in the country. ${ }^{13}$ The sports system became more self- sufficient under the new policy and governance model. Sports commission was restructured into The State General Administration (SGAS) of sports, but still, the government has control over all the levels of sports system in the country.

AUSTRALIA: in the country, Australian Sports Commission (ASC), the federal government entity is the responsible body that looks after sports in the country ${ }^{14}$. It is under the control of the federal minister for sports. It has a separate board. In the year it came out with its first policy,

\footnotetext{
10 John Forster, (2006) "Global sports organisations and their governance", Corporate Governance: The international journal of business in society, Vol. 6 Issue: 1.

${ }^{11}$ Utkarsh Bhatla, The Indian mindset and the need for a change, sportskeeda( September 6, 2012).

${ }^{12}$ Arnout Geraert, Jens Alm and Michael Groll, Good Governance in international sport organisations: an analysis of 35 olympic sports governing bodies

${ }^{13}$ Dali L. Yang, Alan Leung, China: the Politics of sports antidoping in China: Crisis, Governance and International Compliance, China: An international Journal, Vol. 6 No. 1, March 2008.

${ }^{14}$ John Mullins, sports governance in Australia and the leadership of the Australian sports commission, (December 2015).
}

where only 7 sports had to comply with it, but in the year 2015 , it extended the number of sports to comply with the governance model of ASC.

\section{Suggestions for Indian System}

Changes are required to bring good governance for sports in a country like;

- Transparency- to maintain transparency with expenditure and fund utilization, Information like a board of members, administrative officials, and remuneration information must be in public domain.

- Women Representation- it is very important to have sufficient women representation in sports as well as in the administrative bodies, and it is the responsibility of these admin bodies to ensure sufficient representation from women in the board too, to maintain the diversity within the board.

- Plans- there should be fix timelines disclosed which are to be adopted by sports bodies for the purpose of growth and development of sports in future, which is to be achieved in a given specific period of time. These kinds of timelines and plans would be motivational for players and bodies to. Goals to be targeted in future must be predecided, which can be well monitored and regulated by the authorities. Effective implementation would bring positive results in future.

- Committees- to set up specific committees for specific activities relating to sports activities, like for planning, financing, research and development purposes. These committees would look after the particular task, which would bring transparency in work and achieving the common objective.

- Rules and Regulations- like other fields, sports also have conflicts regarding disciplinary, administrative and management issues, to solve this issues governing bodies must set up a common judicial system (tribunal) to deal with sports-related conflicts.

Also, to formulate rules and regulations to aid the judicial body likes tribunals for the proper functioning of the same.

\section{Proposed Changes for India}

First is the inclusion of sports in the concurrent list of the Constitution which was seen as a recreational activity and not as a field of profession, so it was not separated from entertainment and amusement. ${ }^{15}$ There should be the constitution of a sports regulation body, i.e., Sports Regulatory Authority of India (SRAI) which would regulate sports in the country. This was also mentioned in the first draft of the sports policy of 2007, was included to bring the cooperation among the state bodies, NSFs, IOC, and SAI. Other countries like the UK, Australia have well defined regulatory body which forms the regulatory system in countries.

Election commission dedicated to sports-related appointments, and other officials, this would create

\footnotetext{
${ }^{15}$ Manali Kulkarni, developing sports law in India, The Sports Law and Policy Symposium 2017(August 4, 2017).
} 
transparency. As the sports bodies are registered under societies registration act, there is no compliance regarding the composition of committees, members, reports, regulars etc.

As discussed earlier set up a tribunal to resolve the disputes pertaining to sports matter, at present sports federations or sports person has to directly approach the court that is already burdened with their regular cases setting up a sports tribunal will bring speedy justice to parties.

Bring anti-doping laws. It is a report by the World AntiDoping Agency (WADA), that India rank 3rd for the doping offense by athletes. To control this India needs an effective anti-doping law and strict implementation of the same throughout the country.

Women representation and former players to be on board of governing bodies is required. At present, there is no present or former player on the board of these governing bodies. Whereas, very less only about $2-8 \%$ of women representations.

It was revealed in the report, that only one NSF has a former member as its president, and most of the NSFs do not have former sportspersons and players on the board. It is also very important and has become necessary to promote representations and participation in sports and governance by women equally. There should be women representatives on the board of NSFs and other governing bodies of sports. Present percentage of women representation must be increased.

\section{Conclusion}

Evolution of sports from recreational activities, leisure, and entertainment into a profession. Now sports have become a profession for sportsperson in different activities. With time it evolved. Now it is no more just a leisure or time pass but a nation's pride. Sports have a high influence on nation's pride and inherited to each other. So to compete with other nations it is very much required for the government to intervene and regulate the same for better performance and regulation. But, one must take care that these organizations are directly responsible to their international organizations, which do not allow government intervention under their charter. The proposed model for India shows can be the possible solution for this issue. It is clear till now by the workings of federations and authorities that existing model has failed to achieve its objectives and goals. The new model is to be brought without any further delay to solve this problem. Indian culture and our attitude towards sports activities also act as a barrier to sports growth and standards development. Change is not only required at central level or state level but also at block and district levels, these are a highly ignored area for sports education. At block or district level there is no facility for sports training or academy where children or sports person can go and get proper training. This would surely lead to building sporting culture in our country, like other countries where sports training is imparted to children at very young age only. Sports education must be given to students at the school level, to create awareness among them regarding sports activities.
The state needs to take an active part in providing basic and minimum facilities at block levels, to encourage those who want to play or go further in future. At the state level, there should be infrastructural development for sports activities for those who want to pursue further in sports. Enough facilities and coaching should be provided to them. Coaches and support staff must be supportive and create awareness among sportsperson(S) regarding their nutritional diet and non-use of prohibited drugs or any supplements.

Sports administration also needs changes; the present model system is to be entirely changed with the representation of former players on board and sufficient women representation. The election process for the posts of the president or higher posts in the bodies must be transparent. Formation of various different committees to look at specific issues and matters. Also, sports tribunal to resolve the sports-related matter to provide speedy justice. All these changes are necessary for India to compete with other countries at international level and bring transparency in Indian sports governance model

\section{References}

[1] https://tejas.iimb.ac.in/articles/Tejas_September\%20Edi tion_Article\%201.pdf

[2] www.ingovern.com/wpcontent/uploads/2016/.../Governance-of-Sports-inIndia.pdf

[3] www.thehindu.com > Opinion > Columns

[4] www.jsalaw.com/.../World-Sports-Law-ReportLondon-Governance-of-Sports-in-India

[5] https://static.mygov.in/rest/s3fspublic/mygov_14766084941101491.pdf 